Article

\title{
Co-creation of Social Innovation: Corporate Universities as Innovative Strategies for Chinese Firms to Engage with Society
}

\author{
Tachia Chin ${ }^{1}$, , Yin Yang ${ }^{2}$, Pei Zhang ${ }^{2}$, Xiaofen Yu ${ }^{1, *}$ and Luying Cao ${ }^{1} \mathbb{C}$ \\ 1 School of Management, Zhejiang University of Technology, Hangzhou 310023, China; \\ tachia1231@yahoo.com.sg (T.C.); caoly96@163.com (L.C.) \\ 2 School of Management, Hangzhou Dianzi University, Hangzhou 310012, China; \\ youngy_320@163.com (Y.Y.); darkflagxer@outlook.com (P.Z.) \\ * Correspondence: yxf@zjut.edu.cn; Tel.: +86-571-88320889
}

Received: 15 February 2019; Accepted: 28 February 2019; Published: 8 March 2019 updates

\begin{abstract}
Corporate social innovation is a novel, strategic means for enterprise to establish competitive advantage through collaboration with powerful stakeholders, like governments, where firms are simultaneously able to meet social needs and benefit themselves. There is, however limited empirical research investigating how such collaboration enables the co-creation of innovation between firms and society, particularly in emerging markets. In response, this paper takes corporate universities (CUs), a typical manifestation of corporate social innovation, as an example, and explores whether CUs encourage employees to engage in innovation and pro-environmental behaviors, thereby contributing to their firms and local communities in China. Using quantitative methods, we found that employees' participation in CU training/education courses significantly affects employees' innovation and environmentally-friendly behaviors in both work and life, and that it enhances their normative commitment (NC) to organizations. Moreover, this commitment mediates employees' participation in the university program, in terms of both their innovation and pro-environmental behaviors. The main contribution of this paper is to enrich the innovation literature by suggesting a fresh, co-creation mechanism of social innovation between enterprise and government, while offering valuable first-hand evidence in a non-Western context. Our results allow policy makers and stakeholders to gain an in depth understanding of relevant issues.
\end{abstract}

Keywords: social innovation; corporate university; pro-environmental behavior; normative commitment; strategy; co-creation; innovation behavior

\section{Introduction}

Corporate social innovation (CSI) refers to initiatives by firms that involve the use of new ideas, or the application of existing ones, to create social and shareholder values concurrently [1]. CSI has increasingly attracted attention in a variety of fields such as management, education and labor economics [2-4]. Unlike traditional notions of corporate social responsibility (CSR), which mainly focus on philanthropic concerns, CSI-which incorporates the ideas of business innovation into the implementation of CSR - encourages firms to partner with key social stakeholders such as non-profit organizations (NGO) and governments, and through these partnerships, solve societal problems and gain a competitive advantage simultaneously, despite the primary purpose being social $[1,3]$. Although the theoretical foundations of CSI are under-researched [5], the research evidence that exists suggests that CSI programs promote enterprises that actively collaborate and interact with institutions and local communities, and thereby co-create original ideas, products and processes beneficial for the 
greater good (e.g., humanity and the environment). Following this logic, we argue that CSI can be seen as a unique type of strategic investment, as well as an effective innovation strategy for establishing productive relationships with local governments-which is of particular importance to multinational enterprises (MNEs) competing in emerging and low-income countries where financial and economic systems are dominated by the State, and socio-economic inequalities exist.

However, a review of the current literature reveals that hitherto, most papers analyze Western or emerging country-based models, methods and cases of CSI, in which the majority of works adopt qualitative methodology (e.g., [6,7]). There is a dire need for studies that use quantitative evidence, or expand our understanding of CSI activities in different national settings, particularly in less-developed economies with immature institutional mechanisms like Brazil, China, or Vietnam. To fill this gap, this paper uses China, the world's second largest economy, with a different institutional logic and cultural thinking than the West, as a research 'location' to explore relevant issues in depth.

It is worth noting that CSI encompasses a wide range of activities. It is multifaceted in nature and involves diversified social needs (e.g., education, poverty, exclusion, health, employment, environment, etc.) [7-9]. Hence, there are widespread controversies about whether CSI derives from an established social innovation theory or if it is merely a widely-existing, observable, sensory phenomena [5]. Owing to this conceptual vagueness, it was crucial that this study choose an emblematic CSI activity for this paper. Scholars have suggested that the building of corporate universities (CUs) can be seen as a typical manifestation of CSI (education), given that CUs not only assist firms to develop valuable human capital for themselves, but also diffuse critical knowledge to all involved, as external actors [10-14]. For example, the well-known Apple and Huawei universities have helped their companies build strong bonds with local communities in host countries. Following this logic, $\mathrm{CU}$ was chosen as the exemplary 'case study' for this paper.

Taking into account the above-mentioned arguments and research gaps, the main purpose of this paper is to empirically investigate the effectiveness of Chinese firms in using CUs as innovative strategies to co-create social innovation with powerful social stakeholders. We first carried out a literature review to demonstrate the conceptual ambiguity of CSI, followed by an illustration of the vital role CUs play in the co-delivery of social innovation in the Chinese context. Then, we conducted a quantitative study on a large state-owned enterprise (SOE) in China, probing into how this SOE used its corporate university as a strategic platform to resolve social problems, together with local government. In this example, this has involved improving green awareness and enhancing the innovative behaviors of individuals for a recent national initiative.

Overall, the main contribution of this research is to suggest a novel co-creational, co-operative model of social innovation between enterprise and government that draws on CUs as a means of establishing innovative and green human capitals in a non-Western context. We, therefore, enrich the existing body of knowledge across the innovation and education domains, and provide a fruitful, practical implication for firms who aim to build CUs in the Chinese context.

\section{Literature Review}

\subsection{Corporate Social Innovation}

Considering the global economy has experienced intense turbulence and uncertainty in recent years, many governments around the world, including the so-called welfare states, are currently imposing austerity plans to cut public spending, reduce national debts, and are, at the same time, encouraging enterprise to conduct innovative activities that help improve social well-being. Along with this trend of world development, the concept of corporate social innovation (CSI) has received rapidly growing scholarly and policy interest because it underscores the imperative of engaging organizations with social stakeholders. This has propelled firms to co-create and co-deliver innovation with people not only to benefit themselves, but for communities, nations and even humanity $[1,9,15]$. 
Nevertheless, as scholars have indicated [16-20], there are two significant gaps that exist regarding the conceptualization and practicality of CSI in the current literature.

First, CSI remains a polysemous notion because the definition of social innovation is deemed to lack conceptual clarity. Numerous scholars have developed diverse typologies of social innovation from various disciplines and with distinct approaches [5-9]. For example, integrating the perspectives of business innovation and social awareness, Dawson and Daniel (2010, p. 16) define social innovation as "the process of collective idea generation, selection and implementation by people who participate collaboratively to meet social challenges [16]. From an interdisciplinary, pragmatic point of view, Po and Ville (2009) suggest that desirable social innovation means creating new ideas resulting in a positive impact on the quality and/or quantity of life [17]. Several scholars claim that the decisive characteristic of social innovation lies in its innovative combination or configuration of social practices that transform social relations, structure governance and collective empowerment, etc. [21,22]. Combining sociological and economic views, researchers have defined social innovation as a new path of interaction between the economy and society, shedding lights on crucial, yet implicit, social and political dimensions of business innovation [18]. In addition to academic input on CSI, global industrial associations, government think tanks, social policy advisors, NGOs, and the like have also presented various working definitions for CSI. For instance, the Bureau of European Policy Advisors has referred to social innovation as "innovations that are social both in their ends and in their means" and, thus, lead to an effective way to "empower people" and "drive societal change" [23]. The Young Foundation issued an omni-comprehensive definition: "Social innovation means new ideas that work in meeting social goals and have potentially very wide boundaries-from gay partnerships to new ways of using mobile phone texting, and from new lifestyles to new products and services" [24]. According to this discussion, it is obvious that the term 'social innovation' (SI), as well as its derived concept of CSI, remain debatable. Whereas the focus of our paper is the co-creation of social innovation between enterprise and society, we adopt Mirvis et al.'s (2016, p. 8) definition of CSI. It has a particular emphasis on business-to-nonbusiness partnerships that are the foundation of our research: "CSI involves deeper collaboration across functions within a firm with external parties to co-create something new that provides a sustainable solution to social ills" [3]. Simply stated, it encourages firms to combine knowledge, resources and capabilities with their social stakeholders, whereby they can make greater contributions for greater good beyond organizational profits.

Among the studies describing the attributes of a typical social innovation model, Caroli et al.'s (2018) research, based on a comprehensive literature review and an empirical analysis of 545 Italian cases, seems to provide scholars with a relatively feasible tool to more clearly assert the components of the investigated SI activities [5]. This social innovation system of classification includes five main aspects for analysis: social intervention areas; typologies of players; implementation roles of the players; typologies of innovation; and the geographic areas of incidence. According to this categorization, we argue that although the definitional difficulties of CSI remain unresolved, CSI's meaning can be distinguished from some comparatively similar terms such as 'green', 'eco' and 'environmental innovation' $[25,26]$. Specifically, 'social innovation' as the most overarching term can be implemented and promoted by all economic, social and environmental considerations. By way of contrast, 'green' and 'environmental innovation' mainly address environmental sustainability, while 'eco-innovation' focuses more on economic and environmental concerns [25-27].

Second, notwithstanding the significance for enterprise of helping to tackle social inequality and poverty, and improving the well-being of people in contexts where governments suffer large budget deficits and high public debts [14], so far there has been scarce empirical research discussing the effectiveness of corporate social innovation in emerging and low-income countries [6,7]. We argue that this lack of substantial evidence for the benefits of CSI may be due to the fact that CSI originated in capitalist market economies, where for-profit private firms, as the key players, serve as leading innovative agents, proactively mobilising resources and collaborating with stakeholders for social change. Given the success of such cross-sector partnerships, that hinge on the match of core 
competencies and the strategic goals of collaborative partners [28-31], private enterprise in market economies are more inclined to partner with non-profit organizations with similar interests and objectives-rather than public organizations who are usually subject to specific political priorities-to deliver strategic social value and innovation. In contrast, in less-developed, non-market economies, the government often dominates the establishment of cross-sector strategic alliances for social innovation because complex social and environmental problems in such a context are, in general, too intractable for private firms to tackle alone. Consistent with this viewpoint, in China and India, favorite forms of CSI seem to be government-business partnerships where governments usually act as the primary advocate and facilitator who guides all the other stakeholders of this cross-sector alliance to engage in socially-relevant research and development.

In short, despite having gained certain popularity [16-20], the conceptualization, as well as the implementation of CSI, is still in its early stages of development in non-Western countries, which requires a deeper, broader investigation. As such, in this analysis, we used the Chinese economy-that has accomplished stunning growth for decades and is now deemed a successful role model for other emerging and developing countries-as our research setting. Moreover, in view of academic debates on the definition of CSI, this article concentrates on empirically testing the effectiveness of a typical CU phenomenon whereby the main characteristics of CSI can be more clearly identified and examined.

\subsection{Corporate Universities (CU)}

CUs that primarily deliver knowledge-intensive services to employees, in general, exhibit some salient quasi-public good features, just like other higher education institutes do. For example, the devising and implementation of specialized training modules are often conducted in partnership with a firm's external organizations of knowledge, such as the renowned business schools of distinguished universities, and their reliable supply and professional consultancies [10,24]. As a result, one of the key functions of CUs is to promote informal communication and knowledge sharing among a variety of stakeholders. Given their intricate involvement with external parties, CUs today are seen as a unique strategic platform for firms to foster knowledge transfer and accumulation within and beyond organizational boundaries, which is instrumental to a wide network of actors belonging to the same value chain and society [32-35].

As indicated above, in non-democratic countries where government-business partnerships are the most preferable CSI mode, CUs are a typical non-profit unit within, or closely attached to corporations, and have been seen as a particularly suitable agent for firms to create long-term ties with public organizations because they appear to be more ethically acceptable [34-36]. The well-known triple helix analytical framework, "university-industry-government", has also suggested that in imperfect markets, such as some Latin American and Eastern Europe nations, China and Russia, the government generally takes the lead in driving academia and industry as ancillary players to achieve innovative development and structural transformations of a society together $[37,38]$. Although this triple helix system of innovation characterizes the third mission about involvement in socio-economic development of a regular university instead of a CU, it implies that all kinds of higher education institutes should function as a key source of knowledgeable human capital in terms of facilitating the fulfillment of the government-industry joint CSI initiatives. However, due to differences in organizational goals and missions between regular and corporate institutes of higher education, CU may better help put existing knowledge to wider use in management practice, while regular universities pay greater attention to new knowledge creation for regional economic development.

As far as China's research setting is concerned, the building of CU has become a management fad because it is convenient and plausible to employ CUs as a cooperative channel/platform for lubricating bilateral relations between government and enterprise, particularly via work on politically significant CSI projects together. Evidence indicates that the CU number in China has been growing rapidly since early 2000 [12], and has recorded more than 3700 in 2015 [13,14]. This is partly attributed to the Chinese Communist Party (CCP), which launched quite a few policies and rendered vigorous support 
to the establishment of CUs in recent years. Following this policy orientation, an increasing number of Chinese firms have drawn attention to the establishment of CUs, many of whom have adopted CUs as an investment strategy to strengthen their own human capital. Meanwhile, they have developed innovation strategies to engage with society and local communities. For example, several famous CUs including Haier University (https: / /histudy.haier.net/ frontLogin?target=http: / histudy.haier.net/ aiAuth/cePingByPost), JD University E-commerce College (https:/ / xueyuan.jd.com/) and Tencent University (https:/ / daxue.qq.com/) have linked their curriculums to the higher education system within and outside China. They have designed unique, specific training and education programs to satisfy contemporary social needs to foster people's innovative spirit, pro-environmental attitudes and relevant behaviors. The lessons on cultivating intrapreneurship and green awareness have become the most frequently seen courses in Chinese CUs recently. This is because these courses may provide solutions to the two critical issues addressed in China's national initiatives (e.g., the 13th five-year plan proposed by the CCP (http:/ / www.stats.gov.cn/english/PressRelease/201701/t20170120_1455922. $\mathrm{html})$ ), namely to develop innovative capabilities (i.e., concerning mass innovation) and to combat climate change (i.e., concerning environmental protection). These initiatives are designed in response to the challenges facing not only enterprise, but also human kind on a global scale. Hence, CUs are a clear illustration of CSI practices in China.

Nevertheless, despite the rising importance of CUs to stimulate innovation and green awareness among the masses in the Chinese context, there have been a dearth of studies collecting valuable first-hand data and empirically examining whether the CU education programs, especially those co-designed with the government, can indeed enhance employee innovation and environmentally-friendly behaviors and, thereby, benefit society. In response, we adopt an empirical research design and hypothesize:

Hypothesis 1 (H1). Employees' participation in the CU education program is positively related to their innovative behavior in China.

Hypothesis 2 (H2). Employees' participation in the CU education program is positively related to their environmentally-friendly behavior in China.

\subsection{Normative Commitment (NC)}

Normative commitment (NC) is conceptualized as the worker's attachment to the organization based on a moral obligation (mindset of obligation) or a sense of indebtedness to benefits provided by the organization $[39,40]$. In other words, NC reflects a person's need to reciprocate as a result of received benefits. According to the literature, NC, understood as a sense of obligation to remain with an organization, was found to have a stronger effect in non-profit and public organizations than in the private sector, because it mainly involves an implicit psychological contract, rather than a written employment contract [41-43]. Evidence also reveals that NC can also enhance employees' readiness for organizational changes because employees' moral duties urge them to comply with new requests and expectations from their organizations [44].

As noted, the development of the $\mathrm{CU}$ is deemed as an effective, valuable strategic investment made by firms to strengthen worker competencies, whereby their personnel 'capitals' can be better cultivated and nurtured. Following this logic, employees who participate in CU training courses and, thereby, obtain the benefits of learning are very likely to display a higher level of NC due to feelings of indebtedness and gratitude.

Hypothesis 3 (H3). Employees' participation in CU education programs are positively related to their NC levels.

In addition, NC has been discovered to motivate employee citizenship and other positive behaviors [40-42]. Considering we have argued that CUs may significantly influence employees' 
$\mathrm{NC}$ as well as their innovative and environmentally-friendly behaviors, we follow the well-recognized commitment-behavior tandem connection [43,44], and further posit:

Hypothesis 4A (H4a). NC mediates positive relationships between employees' participation in CU education programs and their innovation behaviors.

Hypothesis 4B (H4b). NC mediates positive relationships between employees' participation in CU education programs and their environmentally-friendly behaviors.

\section{Methodology}

\subsection{Case Selection}

To consider the main question posed in this study, we selected a large, listed state-owned pharmaceutical company as our research site in which to conduct quantitative surveys with employees. The Guangxi Wuzhou Zhongheng Group Co. LTD. (hereinafter abbreviated to "Zhongheng"), is located in the Guangxi Province of China. Employees are mostly local residents (more than $70 \%$ of the total 3,000 staff). The company's annual revenue was 2,047 billion yuan (about 294.71 million USD) in 2017. As the biggest and the most influential local drug manufacturer, the top management of Zhongheng has been keen to make a greater contribution to society through supporting the development of, and investment in, local human capital. This strategy can also fortify the quality of the core human capital pool of the company. Along with this line of thought, Zhongheng co-established a CU (Zhongheng University) with the local government (i.e., the Wuzhou municipal government) in June 2017 (http:/ / www.wz-zhongheng.com/?p=3260) and, thus, launched quite a few training and education courses in favor of China's national initiatives to boost mass innovation and environmental awareness. According to the company's record, by virtue of its e-learning platform, less than half of its full-time workers had not participated in the above-mentioned training programs before September 2017. This case study, therefore, is particularly appropriate for our research purpose.

\subsection{Participants Selection and Data Collection}

This research project was financially supported by Zhongheng. It lasted for one year (from September 2017 to September 2018). Before the formal questionnaire surveys were issued, we carried out in-depth interviews with three top management team members (one deputy party secretary who is responsible for managing Zhongheng University, one research and development director and one marketing director). We also interviewed several HR professionals and frontline production workers so that the validity of our hypotheses could be properly tested. Their comments and feedback indicated that our research framework captured what was happening at the university.

With the help of Zhongheng's HR department, we randomly chose 500 workers from the firm's staff list. To reduce extraneous sources of variation and measurement errors, we excluded non-Chinese and part-time employees. Data was collected at two points in time, in line with the longitudinal research design, to lessen the likelihood of common method variance (CMV) [45]. We measured employees' participation in the CU training and education programs to foster innovation and green awareness at Time 1 and the other three variables (i.e., employee NC, innovation and environmental protection behaviors) at Time 2 . The time interval was four months, it generally took about 3 months to finish the specialized courses. The HR department offered us helpful assistance in arranging proper times and places for our research team to undertake the surveys. They also helped us distribute questionnaires to the respondents at both time points. We are grateful to them for this help.

At Time 1, there were a total of 600 workers filling out the questionnaires, but of this number, only 440 employees also completed the questionnaire at Time 2 . After eliminating missing data, we retained 432 usable pair data (Time 1 plus Time 2) with a response rate of $72 \%$. Of the respondents, $88.4 \%$ of the participants were local residents; $34 \%$ completed the above-mentioned CU training courses; $38.4 \%$ 
were male, $61.6 \%$ were female; $72.7 \%$ were married; $61.1 \%$ had junior high school or lower diplomas. The average age of the participants was 36.43 (S.E. $=8.606$ ), while the average tenure was 11.10 years $($ S.E. $=10.115)$.

\subsection{Measurement}

The instruments measuring NC, environmental protection and innovation behaviors used a six-point Likert-type scale (i.e., $1=$ strongly disagree to $6=$ extremely agree) that has no midpoint so as to avoid response bias, because Chinese employees are apt to disguise their true feelings towards their organizations by choosing the midpoint of a scale [41,44]. SPSS 25.0 (IBM, Armonk,) and MPLUS 7.4 (Muthen \& Muthen, Los Angeles, CA, USA) were used to analyze the data.

Employees' participation in the CU training/education programs. This variable is dummy coded as follows: Employees who didn't attend or only completed less than one third of the CU training/education course $(<1 / 3)$ were coded as " 0 ", and those who completed the full course or had participated in more than one third of the course $(\geq 1 / 3)$ were coded as " 1 ".

Innovation behavior. Research on employee innovation behavior is still at the embryonic stage. It often comprises the intentional generation, promotion and realization of novel and useful ideas within a job, a group, or an organization and may, therefore, involve much broader and intricate meanings than individual creativity [46]. The scale selected to evaluate an individual's innovation behavior should be able to embody its multi-faceted nature. We thus chose to adopt a relatively-comprehensive, widely-recognized construct by Vegt and Janssen (2003) [46]. A six-item scale including three sub-dimensions (i.e., idea generation, promotion, and realization) was used to measure a person's innovation behaviors in both work and life (Cronbach's $\alpha=0.958)$. Sample items included "I am willing to create new ideas for improvement" and "I am willing to mobilize support for innovative ideas".

Environmental-friendly behavior. According to the environmental psychology literature, Robertson and Barling's (2013) model on workplace pro-environmental behaviors is currently seen as one of the most recognized [47], as it appears able to characterize an individual's 'green passion' thoroughly. We thus measured environmentally-friendly behaviors using the authors' seven-item scale (Cronbach's $\alpha=0.929$ ). However, we told the respondents to consider the display of such behaviors in both work and life. Sample items included "I print double-sided whenever possible" and "I use reusable eating utensils".

Normative commitment (NC). Recent research suggests that NC may contain two sub-dimensions: indebted obligation and moral duty [39]. Due to ongoing debates on this issue [39,40], we adopted the most widely-applied taxonomy, which was Meyer and Allen's (1997) three-item construct to measure NC in this paper [48] (Cronbach's $\alpha=0.759$ ). Sample items included "I believe in the value of remaining loyal to one's organization" and "I think that wanting to be a company man/woman is still sensible".

Control variables. Referring to previous studies on behavioral outcomes [8,39,41-44], gender (male $=0$, female $=1$ ), age, tenure and education level (junior high school or lower diplomas $=0$, others $=1$ ) were controlled for.

\subsection{Reliability and Validity}

The values of Cronbach's $\alpha$ of all measures were above 0.70 , indicating an acceptable reliability. We then assessed the distinctiveness of the variables used in this research. The assumed 3-factor model displayed the best fit to our data, confirming the nomological validity $\left(\chi 2_{\mathrm{n}}=432=470.84, \mathrm{df}=149\right.$, $\chi 2 / \mathrm{df}=3.160, p<0.001, \mathrm{CFI}=0.960, \mathrm{TLI}=0.952, \mathrm{RMSEA}=0.071, \mathrm{SRMR}=0.040)$. We also checked for the values of construct reliability (CR) and average variance extracted (AVE), and found that all CR and AVE values are above the acceptable values of 0.7 and 0.5 , respectively (see Table 1 ). 
Table 1. Factor loadings of perceptual scales.

\begin{tabular}{|c|c|c|c|c|}
\hline Constructs & Measurement Items & Factor Loadings & AVE & CR \\
\hline \multirow{9}{*}{ Innovative behavior } & I am willing to create new ideas for improvements. & 0.676 & \multirow{9}{*}{0.683} & \multirow{9}{*}{0.951} \\
\hline & $\begin{array}{l}\text { I am willing to search out new methods, techniques, or } \\
\text { instruments at work and in life. }\end{array}$ & 0.694 & & \\
\hline & I am willing to generate original solutions to problems. & 0.742 & & \\
\hline & I am willing to mobilize support for innovative ideas. & 0.853 & & \\
\hline & I am willing acquire approval for innovative ideas & 0.89 & & \\
\hline & $\begin{array}{l}\text { I am willing to make important organizational members } \\
\text { enthusiastic for innovative ideas }\end{array}$ & 0.894 & & \\
\hline & $\begin{array}{l}\text { I am willing to transform innovative ideas into useful } \\
\text { applications. }\end{array}$ & 0.918 & & \\
\hline & $\begin{array}{l}\text { I am willing to introduce innovative ideas into the work } \\
\text { environment and daily life in a systematic way }\end{array}$ & 0.875 & & \\
\hline & I am willing to evaluate the utility of innovate ideas. & 0.856 & & \\
\hline \multirow{3}{*}{ Normative Commitment } & I believe in the value of remaining loyal to one organization. & 0.821 & \multirow{3}{*}{0.517} & \multirow{3}{*}{0.759} \\
\hline & $\begin{array}{l}\text { I think that wanting to be a "company man/woman" is still } \\
\text { sensible. }\end{array}$ & 0.728 & & \\
\hline & $\begin{array}{l}\text { Employees generally move from organization to } \\
\text { organization too often. }\end{array}$ & 0.588 & & \\
\hline \multirow{7}{*}{$\begin{array}{l}\text { Environmental-friendly } \\
\text { Behavior }\end{array}$} & I print double sided whenever possible. & 0.789 & \multirow{7}{*}{0.643} & \multirow{7}{*}{0.927} \\
\hline & I put compostable items in the compost bin. & 0.794 & & \\
\hline & $\begin{array}{l}\text { I put recyclable material (e.g. cans, paper, bottles, batteries) } \\
\text { in the recycling bins. }\end{array}$ & 0.808 & & \\
\hline & $\begin{array}{l}\text { I use reusable eating utensils (e.g. travel coffee mug, water } \\
\text { bottle, reusable containers, reusable cutlery). }\end{array}$ & 0.759 & & \\
\hline & I turn lights off when not in use. & 0.829 & & \\
\hline & $\begin{array}{l}\text { I take part in environmentally friendly programs (e.g. } \\
\text { bike/walk to work day, bring your own local lunch day). }\end{array}$ & 0.831 & & \\
\hline & $\begin{array}{l}\text { I make suggestions about environmentally friendly practices } \\
\text { to managers and/or environmental committees, in an effort } \\
\text { to increase my organization's environmental performance. }\end{array}$ & 0.801 & & \\
\hline
\end{tabular}

\subsection{Construct Validity and Common Method Variance (CMV)}

We conducted the CFA marker technique $[45,49]$ to test whether our results were affected by CMV problems. Considering we had built a 3-factor CFA model to examine construct validity, we then created a first-order latent marker with all of the measures as indicators to the original CFA model to address the CMV issues. This latent variable approach allowed us to control for the effects of a single unmeasured latent method factor. In comparison with the original three-factor model mentioned above, the new construct with the latent CMV factor still fit the data well $\left(\chi 2_{\mathrm{n}}=432=470.84, \mathrm{df}=148\right.$, $\chi^{2} / \mathrm{df}=3.259, p<0.001, \mathrm{CFI}=0.958, \mathrm{TLI}=0.950$, RMSEA $=0.072$, SRMR=0.056) and did not make any significant differences $\left(\triangle \chi^{2}=11.42, p>0.050\right)$. Therefore, CMV is unlikely to be a major threat in this study.

\section{Results}

Table 2 presents the descriptive statistics (i.e., the mean, variance and correlation coefficients) of the perceptual variables used in our study. The inter-construct correlations were smaller than the values of the square roots of AVE in all cases. According to the correlation coefficients, participation in the CU programs showed a significant positive correlation with $\mathrm{NC}$, innovation and environmentally-friendly behaviors, respectively. This result offers preliminary evidence for validating our hypotheses. 
Table 2. Descriptive statistics and correlations.

\begin{tabular}{ccccccccc}
\hline Variable & Gender & Age & Tenure & Edu & CU & NC & EIB & EFB \\
\hline Gender & 1 & & & & & & & \\
Age & 0.028 & 1 & & & & & & \\
Tenure & -0.035 & $0.712^{* *}$ & 1 & & & & & \\
Education & $-0.187^{* *}$ & $-0.236^{* *}$ & $-0.147^{* *}$ & 1 & & & & \\
CU & 0.045 & -0.053 & $-0.100^{*}$ & 0.059 & 1 & & & \\
NC & $0.105^{*}$ & 0.058 & 0.011 & -0.032 & $0.424^{* *}$ & 0.719 & & \\
EIB & 0.051 & 0.045 & -0.026 & 0.029 & $0.697^{* *}$ & $0.564^{* *}$ & 0.826 & \\
EFB & $0.124^{*}$ & 0.049 & 0.006 & -0.023 & $0.667^{* *}$ & $0.617^{* *}$ & $0.736^{* *}$ & 0.802 \\
Mean & 0.616 & 36.433 & 11.097 & 2.060 & 0.340 & 14.711 & 5.080 & 5.148 \\
SD & 0.487 & 8.606 & 10.115 & 0.917 & 0.474 & 2.248 & 0.517 & 0.481 \\
\hline
\end{tabular}

Note: $\mathrm{n}=432 ;{ }^{* *}$ Correlation is significant at the 0.01 level (two-tailed); ${ }^{*}$ Correlation is significant at the 0.05 level (two-tailed).

\section{Test of Hypotheses}

As mentioned, we used path analysis to test our hypotheses with SPSS 25.0 and Mplus 7.4 [49]. Figure 1 presents the results of all path analyses, including the mediation framework. Hypotheses 1 and 2 predicted a positive relationship of employees' participation in the CU programs (hereafter referred to as $\mathrm{CU}$ ) with employees' innovation behavior and environmentally-friendly behaviors. The path model results indicated that $\mathrm{CU}$ was significantly and positively associated with employee innovation behaviors $(\gamma=0.506, p<0.001)$, environmentally-friendly behaviors $(\gamma=0.423, p<0.001)$, and NC $(\gamma=0.662, p<0.001)$, respectively. Thus, Hypotheses 1,2 and 3 are fully supported.

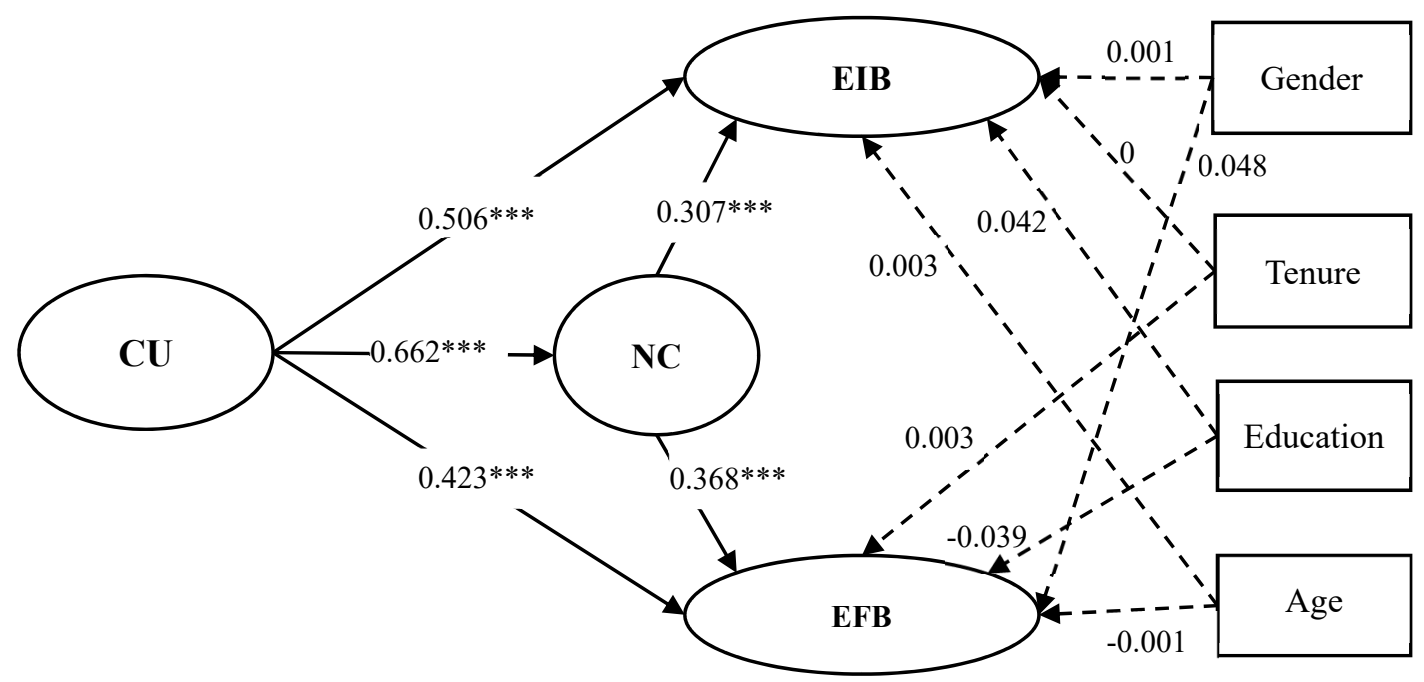

Figure 1. The hypothesized model figure (Note: ${ }^{* * *}$ Correlation is significant at the 0.001 level (three-tailed); The rectangle represents the control variable).

Following Preacher et al. (2010) [50], we also included the direct path in our mediation model. Hypotheses $4 \mathrm{a}$ and $4 \mathrm{~b}$ predicted that NC partially mediates the relationships between CU and innovation behaviors and environmentally-friendly behaviors. We thus calculated $95 \%$ Monte Carlo confidence intervals $(\mathrm{CI})$ by using the bootstrapping approach with 5,000 repetitions. The indirect effect between $C U$ and innovation behaviors via NC was 0.212 and the 95 percent $C I[0.152,0.255]$ did not include zero, while the indirect effect between CU and environmentally-friendly behaviors via NC was 0.255 and the 95 percent CI $[0.187,0.300]$ did not include zero. Therefore, Hypotheses $4 \mathrm{a}$ and $4 \mathrm{~b}$ are also fully supported. 


\section{Discussion}

In summary, according to the findings presented above, our four hypotheses have been fully examined. Employees' participation in the CU education program is significantly related to their innovation and environmentally-friendly behaviors, which suggests that the employees who have participated in the $\mathrm{CU}$ training programs tend to engage in more innovation and environmentally-friendly behaviors in both their work and daily life. Although individual innovation and pro-environmental behaviors are deemed to benefit society in quite a few ways $[11,28,51,52]$, this claim still requires more potent empirical support [16-19]. Our results provide precious first-hand evidence to bolster this assertion, as well as answering our research question: The development of CUs can indeed be regarded as an effective, pragmatic strategy for Chinese firms to jointly develop social innovation strategies with the government. Our findings also indicate that under China's unique socialist market economic system, CUs-despite being launched by companies-are subject to strong state intervention. This, to a certain extent, can enrich our understanding of how CUs can engage with powerful stakeholders in non-Western institutional settings [33-35].

Moreover, we found that employees' participation in CU training/education programs are positively associated with their levels of $\mathrm{NC}$, and that the direct effects of $\mathrm{CU}$ on employees' innovation and pro-environmental behaviors are mediated by the level of their NC. This mediation analysis suggests that if an employee's NC is low, the positive influence of CUs may not be effectively translated into an individual's exhibition of innovation and pro-environmental behaviors. Related to this point, we also argue that if $\mathrm{CU}$ training and/or education courses are able to induce participating employees into a mindset of 'obligation' towards the company, this may fortify the employees' commitment and/or attachment to the organization, which may be a feasible means for firms to reduce their turnover and thereby retain good staff.

Apart from the above-mentioned findings, we also discovered that NU significantly and positively affects employee innovation behaviors $(\gamma=0.307, p<0.001)$, as well as environmental-friendly behaviors $(\gamma=0.368, p<0.001)$, respectively (please refer to Figure 1$)$. Our results thus render empirical support to prior research that found that employees' NC is significantly related to their behavioral outcomes [39,40,42-44], and, thus, underscores the important role of NC in organizations.

\section{Conclusions, Limitation and Future Research}

Overall, this research provides new insights into CSI practices in the context of Chinese corporate universities. We make three unique contributions. First and foremost, we draw on valuable first-hand data to articulate the effectiveness of a novel co-creation mechanism of social innovation between enterprise and government in a distinctive Chinese, CU context. Although the research literature illustrates a variety of CU-societal interactions $[11,14,53]$, there have been limited studies explicitly linking the function of CUs with the implementation of social innovation in socialist market/non-market economies like China. However, in a transitional environment, relatively high institutional costs usually hinder the mobility of scarce resources and, hence, CSI seems to be particularly vital in helping eliminate the perceived social unfairness of resource distribution. Viewed from this angle, this current study, using the example of China, the world's largest emerging country as a background, provides new insights into institutionalizing the concept of social innovation from a view of cross-sector partnership in a non-Western context, and thereby enriches the theoretical knowledge across innovation and education domains.

Second, we contribute to the organizational behavior $(\mathrm{OB})$ literature by identifying the role of $\mathrm{CU}$ in promoting NC as well as the intervening influence of NC on the CU behavioral outcome relationships. Research probing into the roles of CUs in management practices usually focuses on demonstrating how CUs interrelate with knowledge-related activities in organizations such as organizational learning, knowledge transfer, the development of heterogeneous human capitals, etc. [11,12,51-53]. In this sense, our paper partly broadens the horizon of research by adopting a cross-disciplinary perspective to connect CUs with employees' commitment and CSI-oriented behaviors 
As far as suggesting practical implications, while the building of CUs has become a prevalent trend among Chinese enterprises, our results allow policy makers and other stakeholders, to gain a better, in depth understanding of relevant issues. While CSI has been viewed as a respectable field of enquiry $[3,16,18,19]$, it is imperative that practitioners more closely collaborate with academics so as to devise original or 'novel' CSI projects that break the boundary between public and private sectors and industries. Our research sheds light on the importance of a typical, quasi-public good, the $\mathrm{CU}$, and how it might build a bridge between theory and practice. It is also worth noting how, in this study, the triple helix "university-industry-government" framework has unveiled the occurrence of CSI activities at the intersection of three spheres: higher education, public organization and enterprise $[37,38]$. Our study, which focuses on CUs rather than regular universities, may advance the sphere of knowledge to manifest new types of actors, links and structures within the interacting mechanisms. Additionally, notwithstanding China has built the world's largest higher education (HE) system with more than 2,577 public HE providers (including 292 adult HE affiliations) and 734 private HE institutes (Chin et al., 2018) [14], the demand for HE providers is still growing. Viewed from this angle, our research also bears a deep meaning to practitioners in China's booming education industry, as CUs may offer an alternative platform for them to exert their abilities as well as develop their careers in a non-conventional way.

Nevertheless, a few limitations of this study should be noted. We acknowledge that the case for this study was selected based on the reasons of appropriateness rather than representativeness, and that our research design led to a sample involving only one large state-owned company in China. In light of this, we cannot ensure the generalizability and transferability of our findings. Future research is needed to include more samples with idiosyncratic characteristics to enable more comprehensive hypotheses on CUs and so that CSI can be further developed and tested. Whereas our research investigates the effectiveness of a Chinese firm in adopting CUs as a strategy to achieve innovation and environmental objectives, future research might examine what capabilities are instrumental in the co-creation of social innovation between companies and the government. In addition, the different phases and different partners in the co-creation of social innovation might also be taken into consideration. While CSI can encompass innovation activities with an environmental concern, it can also focus on various other social and economic impacts. The contribution of this research, with a focus just on employee innovation and pro-environmental behaviors, is therefore limited in scope. It is necessary for future scholars to further expand the boundaries of the CSI phenomenon, whereby the possible stakeholders of a specific CSI project can be more clearly identified, and the ways they co-create and co-deliver social innovation can be more thoroughly understood.

Author Contributions: T.C. contributed ideas to the article and prepared the theoretical framework; T.C., Y.Y. and P.Z. performed the interviews and survey; T.C., Y.Y. and P.Z. analyzed the data; T.C., and Y.Y. wrote the original draft; X.Y. supervised the research; L.C. contributed revisions to subsequent iterations of the article.

Funding: This research was funded by the National Natural Science Foundation of China (project 71774144).

Acknowledgments: We would like to express our sincere gratitude to the support given from Party Secretary Jingbo OUYANG, Vice President Dr. Richard TSUEI, Vice Party Secretary Haibo CHEN as well as the HR staff members at the Guangxi Wuzhou Zhongheng Group. We also want to thank all the members of our research team, particularly Lingyan HU, Zili JIANG, Jin YE, and Bufan DENG, for their great effort in doing the survey and completing the report.

Conflicts of Interest: The authors declare no conflict of interest.

\section{References}

1. Herrera, M.E.B. Creating competitive advantage by institutionalizing corporate social innovation. J. Bus. Res. 2015, 68, 1468-1474. [CrossRef]

2. Weber, J.M. Social innovation and social enterprise in the classroom: Frances Westley on bringing clarity and rigor to program design. Acad. Manag. Learn. Educ. 2012, 11, 409-418. [CrossRef] 
3. Mirvis, P.; Herrera, M.E.B.; Googins, B.; Albareda, L. Corporate social innovation: How firms learn to innovate for the greater good. J. Bus. Res. 2016, 29, 5014-5021. [CrossRef]

4. Ims, K.J.; Zsolnai, L. Ethics of social innovation. Soc. Bus. Rev. 2014, 9, 186-194. [CrossRef]

5. Caroli, M.G.; Fracassi, E.; Maiolini, R.; Carnini Pulino, S. Exploring social innovation components and attributes: A taxonomy proposal. J. Soc. Entrep. 2018, 9, 94-109. [CrossRef]

6. Bhatt, P.; Ahmad, A.J. Financial social innovation to engage the economically marginalized: Insights from an Indian case study. Entrep. Reg. Dev. 2017, 29, 391-413. [CrossRef]

7. Chell, E.K.N.; Karatas-Ozkan, M. Social entrepreneurship and enterprise: International and Innovation Perspectives. Entrep. Reg. Dev. 2010, 22, 485-493. [CrossRef]

8. Vezina, M.; Selma, M.B.; Malo, M.C. Exploring the social innovation process in a large market based social enterprise: A dynamic capabilities approach. Manag. Decis. 2018. [CrossRef]

9. Milley, P.; Szijarto, B.; Svensson, K.; Cousins, B. The evaluation of social innovation: A review and integration of the current empirical knowledge base. Evaluation 2018, 24, 237-258. [CrossRef]

10. Blass, E. The rise and rise of the corporate university. J. Eur. Ind. Train. 2005, 29, 58-74. [CrossRef]

11. Antonelli, G.; Cappiello, G.; Pedrini, G. The corporate university in the European utility industries. Util. Policy 2013, 25, 33-41. [CrossRef]

12. Wright, P.; Szeto, W.F.; Cheng, L.T. Guanxi and professional conduct in China: A management development perspective. Int. J. Hum. Resour. Manag. 2002, 13, 156-182. [CrossRef]

13. Bu, J.; Song, Y. Chinese Corporate University in the Period of Reforming: Theory and Practice; China Renmin University Press: Beijing, China, 2016.

14. Chin, T.; Rowley, C.; Gordon, R.; Wang, S. Chinese strategic thinking on competitive conflict: Insights from Yin-Yang harmony cognition. Int. J. Confl. Manag. 2018, 29, 683-704. [CrossRef]

15. Saji, B.S. Social innovation model for business performance and innovation. Int. J. Prod. Perform. Manag. 2016, 65, 256-274. [CrossRef]

16. Dawson, P.; Daniel, L. Understanding social innovation: A provisional framework. Int. J. Technol. Manag. 2010, 51, 9-21. [CrossRef]

17. Pol., E.; Ville, S. Social innovation: Buzz word or enduring term? J. Socio-Econ. 2009, 38, 878-885. [CrossRef]

18. van der Have, R.P.; Rubalcaba, L. Social innovation research: An emerging area of innovation studies? Res. Policy 2016, 45, 1923-1935. [CrossRef]

19. Cajaiba-Santana, G. Social innovation: Moving the field forward: A conceptual framework. Technol. Forecast. Soc. Chang. 2014, 82, 42-51. [CrossRef]

20. Chen, X.; Tai, C.-T.; Wu, L.; Tsai, F.-S.; Srimanus, K. Business models for social innovation of municipal solid waste recycling companies: Comparison of two business cases in Thailand and Taiwan. Sustainability 2018, 10, 1009. [CrossRef]

21. Avelino, F.; Wittmayer, J.M.; Pel, B.; Weaver, P.; Dumitru, A.; Haxeltine, A.; Kemp, R.; Jørgensen, M.S.; Bauler, T.; Ruijsink, S.; et al. Transformative social innovation and (dis) empowerment. Technol. Forecast. Soc. Chang. 2017. [CrossRef]

22. Howaldt, J.; Kopp, R. Shaping social innovation by social research. In Challenge Social Innovation; Springer: Berlin/Heidelberg, Germany, 2012.

23. BEPA (Bureau of European Policy Advisors). Empowering people, driving change. In Social Innovation in the European Union; European Commission: Luxembourg City, Luxembourg, 2010.

24. The Young Foundation. Social Innovation: What It Is, Why It Matters, How It Can Be Accelerated. 2007. Available online: https: / /youngfoundation.org/ (accessed on 21 October 2018).

25. Schiederig, T.; Tietze, F.; Herstatt, C. Green innovation in technology and innovation management-An exploratory literature review. RED Manag. 2012, 42, 180-192.

26. Rennings, K. Redefining innovation-eco-innovation research and the contribution from ecological economies. Ecol. Econ. 2000, 32, 319-332. [CrossRef]

27. De Marchi, V. Environmental innovation and R \& D cooperation: Empirical evidence from Spanish manufacturing firms. Res. Policy 2012, 41, 614-623.

28. Selsky, J.W.; Parker, B. Cross-sector partnerships to address social issues: Challenges to theory and practice. J. Manag. 2005, 31, 849-873. [CrossRef]

29. Babiak, K.; Thibault, L. Challenges in multiple cross-sector partnerships. Nonprofit Volunt. Sect. Q. 2009, 38, 117-143. [CrossRef] 
30. Seitanidi, M.M.; Koufopoulos, D.N.; Palmer, P. Partnership formation for change: Indicators for transformative potential in cross sector social partnerships. J. Bus. Ethics 2010, 94, 139-161. [CrossRef]

31. Le Ber, M.J.; Branzei, O. (Re) forming strategic cross-sector partnerships: Relational processes of social innovation. Bus. Soc. 2010, 49, 140-172. [CrossRef]

32. Scarso, E. Corporate universities as knowledge management tools. VINE J. Inf. Knowl. Manag. Syst. 2018, 47, 538-554. [CrossRef]

33. Parshakov, P.; Shakina, E.A. With or without CU: A comparative study of efficiency of European and Russian corporate universities. J. Intellect. Cap. 2018, 19, 96-111. [CrossRef]

34. Prince, C.; Stewart, J. Corporate universities-an analytical framework. J. Manag. Dev. 2002, $21,794-811$. [CrossRef]

35. Shaw, S. The corporate university: Global or local phenomenon? J. Eur. Ind. Train. 2005, 29, 21-39. [CrossRef]

36. Rademakers, M. Corporate universities: Driving force of knowledge innovation. J. Workplace Learn. 2005, 17, 130-136. [CrossRef]

37. Ranga, M.; Etzkowitz, H. Triple helix systems: An analytical framework for innovation policy and practice in the knowledge society. Ind. High. Educ. 2013, 27, 237-262. [CrossRef]

38. Etzkowitz, H.; Ranga, M.; Dzisah, J. Wither the university? The Novum Trivium and the transition from indutrial to knowledge society. Soc. Sci. Inf. 2012, 51, 143-164. [CrossRef]

39. Meyer, J.P.; Parfyonova, N.M. Normative commitment in the workplace: A theoretical analysis and re-conceptualization. Hum. Resour. Manag. Rev. 2010, 20, 283-294. [CrossRef]

40. Jaros, S. A critique of normative commitment in management research. Manag. Res. Rev. 2017, 40, 517-537. [CrossRef]

41. Chin, T. Harmony and organization citizenship behavior in Chinese organizations. Int. J. Hum. Resour. Manag. 2015, 26, 1110-1129. [CrossRef]

42. McCallum, S.Y.; Forret, M.L.; Wolff, H.-G. Internal and external networking behavior: An investigation of relationships with affective, continuance, and normative commitment. Career Dev. Int. 2014, 19, 595-614. [CrossRef]

43. Lee, C.-H.; Wang, M.-L.; Liu, M.-S. When and How Does Psychological Voice Climate Influence Individual Change Readiness? The Mediating Role of Normative Commitment and the Moderating Role of Work Engagement. Front. Psychol. 2017, 8, 1737. [CrossRef]

44. Chin, T. Harmony as means to enhance affective commitment in a Chinese organization. Cross Cult. Manag. 2014, 21, 326-343. [CrossRef]

45. Podsakoff, P.M.; Mackenzie, S.B.; Podsakoff, N.P. Sources of Method Bias in Social Science Research and Recommendations on How to Control It. Annu. Rev. Psychol. 2012, 63, 539-569. [CrossRef] [PubMed]

46. Vegt, G.S.V.S.; Janssen, O. Joint impact of interdependence and group diversity on innovation. J. Manag. 2003, 29, 729-751.

47. Robertson, J.; Barling, J. Greening organizations through leaders' influence on employees' pro-environmental behaviors. J. Organ. Behav. 2013, 34, 176-194. [CrossRef]

48. Meyer, J.P.; Allen, N.J. Commitment in the Workplace: Theory, Research, and Application; Sage: Thousand Oaks, CA, USA, 1997.

49. Muthen, L.K.; Muthen, B.O. Mplus User's Guide, 7th ed.; Muthen \& Muthen: Los Angeles, CA, USA, 2012.

50. Preacher, K.J.; Zyphur, M.J.; Zhang, Z. A general multilevel sem framework for assessing multilevel mediation. Psychol. Methods 2010, 15, 209-233. [CrossRef] [PubMed]

51. Chin, T.; Liu, R.-H.; Yang, X. Reverse internationalization in Chinese firms: A study of how global startup OEMs seek to compete domestically. Asia Pac. Bus. Rev. 2016, 22, 201-219. [CrossRef]

52. Zhong, W.; Chin, T. The role of translation in cross-cultural knowledge transfer within a MNE's business networks: A 3D-hierarchical model in China. Chin. Manag. Stud. 2015, 9, 589-610. [CrossRef]

53. Makelvey, M.; Zaring, O. Co-delivery of social innovations: Exploring the university role in academic engagement with society. Ind. Innov. 2017, 25, 594-611. [CrossRef]

(C) 2019 by the authors. Licensee MDPI, Basel, Switzerland. This article is an open access article distributed under the terms and conditions of the Creative Commons Attribution (CC BY) license (http:/ / creativecommons.org/licenses/by/4.0/). 